\title{
Degradation of Trichloroethylene Contaminated Soil by Zero-Valent Iron Nanoparticles
}

\author{
Amira Kamal Ibrahem, ${ }^{1}$ Thanaa Abdel Moghny, ${ }^{2}$ \\ Yasser Mohamed Mustafa, ${ }^{3}$ Nermine Elsyed Maysour, ${ }^{2}$ \\ Farida Mohamed Saad El Din El Dars, ${ }^{4}$ and Reham Farouk Hassan ${ }^{4}$ \\ ${ }^{1}$ Sahara Petroleum Service Company (Sapesco), Zahraa El-Maadi-Industrial Area, Cairo 11742, Egypt \\ ${ }^{2}$ Applications Department, Egyptian Petroleum Research Institute (EPRI), Ahmed El-Zomer, P.O. Box 11727, Nasr City, Cairo, Egypt \\ ${ }^{3}$ Evaluation and Analysis Department, Egyptian Petroleum Research Institute, Ahmed El-Zomer, P.O. Box 11727, Nasr City, Cairo, \\ Egypt \\ ${ }^{4}$ Analytical Chemistry Departments, Faculty of Science, Helwan University, Cairo 11795, Egypt
}

Correspondence should be addressed to Thanaa Abdel Moghny, thanaa_h@yahoo.com

Received 26 June 2012; Accepted 16 August 2012

Academic Editors: B. J. Allred and W. Ding

Copyright (c) 2012 Amira Kamal Ibrahem et al. This is an open access article distributed under the Creative Commons Attribution License, which permits unrestricted use, distribution, and reproduction in any medium, provided the original work is properly cited.

\begin{abstract}
Trichloroethylene (TCE) contaminated soil has received extensive attention in the environmental issues. Nanoscale zero-valent iron (NZVI) is considered as an excellent reduction catalyst due to fast degradation of chlorinated solvents. Therefore, this paper aims to evaluate TCE removal from soil by surfactant modified nanoscale zero-valent iron (SNZVI). In this respect, fixed $500 \mathrm{~g}$ soil having a diameter range $0.5-1 \mathrm{~mm}$ was polluted with $10 \mathrm{~mL}$ TCE and put inside glass column of $2.5 \mathrm{~cm}$ diameter $\times 300 \mathrm{~cm}$ length. The NZVI solution was prepared from reduction of $\mathrm{FeCL}_{3}$ by $\mathrm{NaBH}_{4}$ and coating with $2.5 \mathrm{~g}$ nonionic surfactant (Tween 85) to produce iron nanoparticle concentration of $0.1 \mathrm{~g} / \mathrm{L}$. The prepared iron nanoparticle was poured into contaminated soil and left to stir at a constant rate for 24 days. The reductive dechlorination of TCE was measured as a function of increasing chloride ion. It was found that the TCE dechlorination in the presence of iron surfaces displayed pseudo first-order kinetics. The TCE degradation rate constant $\left(K_{\text {obs }}\right)$ is $4 \times 10^{-4} \mathrm{~h}^{-1}$. Also, about $30 \%$ of TCE was removed within initial 6 days. The obtained specific rate constant $\left(K_{\mathrm{SA}}\right)$ was $6.081 \times 10^{-4} \mathrm{~L} \cdot \mathrm{h}^{-1} \cdot \mathrm{m}^{-2}$ and is lower than other studies carried into aqueous phase by about 23 orders of magnitude. Finally, the SNZVI was found to be effective and fully removed to TCE within 456 hours.
\end{abstract}

\section{Introduction}

The remediation of contaminated soils is becoming an increasing environmental problem with serious implications. More specifically, soils contaminated with hydrocarbons represent one of the most difficult challenges for remediation experts. Some treatment and clean-up techniques of oily shorelines may include washing or manual removal; often these methods depend on natural environmental processes that act on the oil. Physical in situ shoreline treatment methods include mixing (also known as tilling or aeration), sediment relocation (or surf washing), and burning. Chemical and biological in situ shoreline treatment methods include the use of chemical agents to alter the physical or chemical properties of the oil as well as use of nutrients to enhance bioremediation. Natural recovery, or natural attenuation, is an in situ response option that allows the oiled shoreline to recover without intervention [1].

Trichloroethylene (TCE) is often categorized as dense nonaqueous phase liquid (DNAPL) for its low aqueous solubility and greater density than water. Once released into the subsurface environment, TCE will distribute between soil and water. Yet, soil-sorbed TCE can be slowly released back into groundwater, rendering TCE a long-term threat to the environment and human health $[2,3]$.

It is well known that soil sorption can inhibit or limit natural attenuation or bioavailability of TCE. In situ remediation techniques for the treatment of dense nonaqueous 
phase liquids (DNAPL), such as trichloroethylene (TCE), and its daughter products are few. The use of iron in reductively dehalogenation chlorinated compounds is a proven method of remediation of such solvents. Removal of TCE by chemical reduction has been a challenging task for decades. Among various technologies for the dechlorination of TCE, zero-valent iron (ZVI; Fe0) particles appear to be one of the most promising technologies. However, microsized $\mathrm{Fe} 0$ particles have been found to show a low TCE reduction rate with half-lives in the order of days or longer. To enhance the dechlorination rate, many researchers have paid their attention to increasing the surface area of ZVI, so the nanosized ZVI particles can be considered as the best reductive degradation for chlorinated organic compounds in soil and groundwater. The proposed reaction pathways for TCE degradation are $\beta$-elimination (primary), hydrogenation (minor), and hydrogenolysis (minor). The first two mechanisms explain the formation of ethene and ethane, while a minor portion of TCE decomposed by the third can result in the formation of cis-dichloroethene (DCE) and vinyl chloride (VC) [4-6].

Previous studies have demonstrated that reducing conventional ZVI particle size to $10-100 \mathrm{~nm}$ increases surface area and reactivity and potentially simplifies delivery via injection to contaminated zones located well below the ground surface [7-9]. NZVI can be synthesized via the borohydride-catalyzed reduction of dissolved Fe (II) or Fe (III) [10]. Moreover, Wang and Zhang [7] showed that freshly synthesized NZVI exhibits a significantly greater surface reactivity than commercial iron powders.

Studies on the transport of ZVI nanoparticles in soils have been largely preliminary and limited to demonstration or optimization of the mobility of stabilized ZVI nanoparticles in porous media. In general, nonstabilized ZVI particles, which are present as agglomerates, are found not transportable in soils or even fine glass beads $[11,12]$. A number of field tests have been reported to test the effectiveness of the in situ injection of ZVI nanoparticles. Elliott and Zhang [13] reported that Fe-Pd nanoparticles of $100-200 \mathrm{~nm}$ were able to remove TCE by $1.5-96.5 \%$ at a contaminated site in a 4-week operation. Quinn et al. [14] reported that ZVI particles emulsified with a nonionic surfactant sorbitan trioleate at a NASA site decreased TCE concentrations in soil by $87-99.5 \%$ in 90 days, and TCE concentration in groundwater was lowered by $57-100 \%$ at all depths in 5 months. However, the greatest technical obstacle for implementing this technology remains in the limited particle mobility in the subsurface. Surfactant-enhanced desorption has been widely studied for enhanced dissolution and removal of soil-sorbed hydrophobic contaminants [1517]. Due to their amphiphilic nature, surfactants are known to enhance the solubilization and mobilization of soil-sorbed contaminants. Cationic surfactant HDTMA was observed to enhance chlorinated solvent degradation with microsized ZVI powders at concentrations under its critical micelle concentration (CMC) due to increased TCE adsorption on ZVI nanoparticles [18].

Many studies have revealed the effectiveness of ZVI nanoparticles for degradation of chlorinated hydrocarbons in homogeneous systems, little is known about the effectiveness for degrading soil-sorbed contaminants. Therefore, the objective of the present paper is to investigate TCE removal from soil by surfactant modified nanoscale zero-valent iron (SNZVI) as follows: (1) preparation and characterization of SNZVI, (2) determining the reductive dechlorination of TCE in porous media as a function of increasing the concentration of chloride ion.

\section{Materials and Methods}

2.1. Chemicals. Two high purity chemical fine granular sodium borohydride $\mathrm{NaBH}_{4}$ from Merck schuchardt OHG 85662 Hohen brunn, Germany, Ferric Chloride Hexahydrate $\mathrm{FeCl}_{3} \cdot 6 \mathrm{H}_{2} \mathrm{O}$ were purchased from $\mathrm{CDH}$ Laboratory Reagent Central Drug House; TCE standards were purchased from Egyptian Local market.

2.2. Soil. Coarse sand taken from Suze desert in East Egypt with diameter range from 0.5 to $1 \mathrm{~mm}$ with porosity equal $25 \%$ was used as the porous medium. Before use, the soils were sieved through a standard sieve of $2 \mathrm{~mm}$ openings and then washed with tap water to remove fine colloids and water-soluble compositions, which can adsorb significant amounts of TCE but are hardly separable from water. The washed soils can be completely separated from water through centrifugation at $400 \mathrm{~g}$-force. Finally the soils were air-dried at room temperature and stored for use.

2.3. Preparation of Contaminated Soil. A fixed TCE solution at concentration of $10 \mathrm{~g}$ was delivered in a small volume of methanol and mixed well with $500 \mathrm{~g}$ coarse sand $(0.5-1 \mathrm{~mm})$. Then this blend was left for $48 \mathrm{~h}$ for rapid phase sorption. To inhibit any possible biological activities during the sorption tests, $0.2 \mathrm{~g} / \mathrm{L}$ of $\mathrm{NaN}_{3}$ was included in the solutions. The contaminated soil was kept out in a closed bottle, at room temperature for $12 \mathrm{~h}$ before entering inside glass column.

\subsection{Determination of TCE Concentrations as a Function} of Critical Micelle Concentration. The ability of surfactant solutions to uptake the TCE from soil to aqueous phase was investigated as follows. In the batch test, nonionic surfactant solutions (Tween 85) were prepared at concentrations ranging from five times lower and higher than its calculated critical micelle concentration (CMC). Then each concentration was poured into $100 \mathrm{~mL}$ volumetric flask filled with $10 \mathrm{~g}$ coarse sand $(0.5-1 \mathrm{~mm})$ contaminated with $1 \mathrm{~g}$ TCE. Then the solutions were continuously shaken in rotary shaker ( $150 \mathrm{rpm})$ for 30 minutes. The sample flasks were then allowed to settle for $24 \mathrm{~h}$ for phase separation and filtration. The TCE concentration in the aqueous phase was analyzed as a function of critical micelle concentrations of surfactant using two techniques HPLC and Turbid meter, respectively. In this respect, Waters HPLC 600E equipped with dual UV absorbance detector Waters 2487 and auto sampler Waters 717 plus attached to computerized system with Millennium 3.2 software were used. Part of the samples was extracted at selected time intervals with acetonitrile: water $(80 / 20, \mathrm{v} / \mathrm{v})$. 


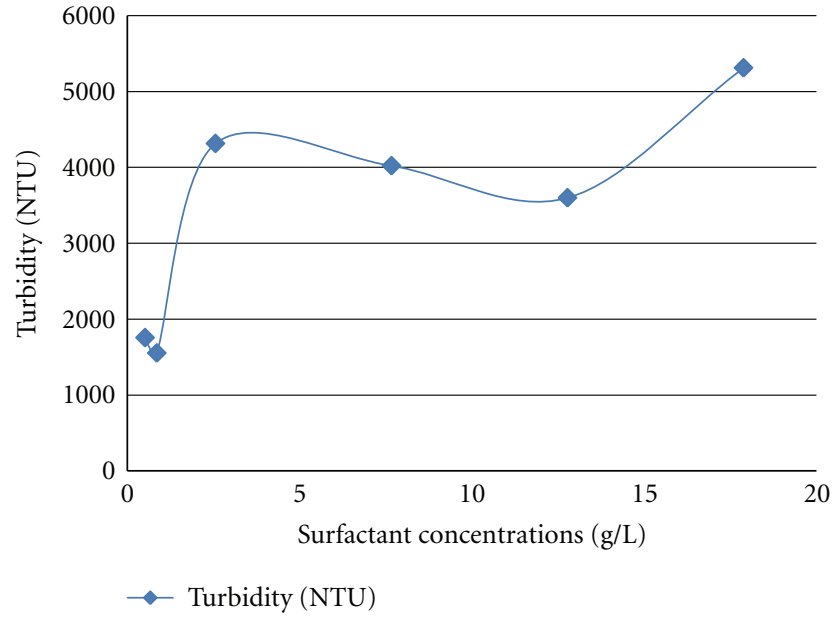

FIgURE 1: Critical micelle concentrations of nonionic surfactant versus TCE distribution in the aqueous phase as a function of turbidity (NTU).

A Supelcosil column LC-PAH, $5 \mu \mathrm{m}$ particles, $15 \mathrm{~cm}$ length, and $4.6 \mathrm{~mm}$, ID was used at flow rate of $1.0 \mathrm{~mL} / \mathrm{min}$, and the detector was set at $214 \mathrm{~nm}$. Then the second portion was withdrawn and their turbidity was determined using Thermo Scientific Orian AOUA fast AQ4500 Turbid meter and was calibrated according to EPA. 180.1, using SDVB turbidity standards.

2.4.1. CMC of Surfactant. The TCE removal as a function of critical micelle concentration in the presence of (Tween 85) surfactants at a range of concentrations (from sub- to supracritical micelle concentrations by \pm 5 ) was examined in batch experiments. Critical (Tween 85) concentration was measured with Thermo Scientific Orian AOUAfast AQ4500 Turbid meter at a wavelength of $230 \mathrm{~nm}$. The relation between surfactant concentration and turbidity (NTU) exhibited in Figure 1 was observed in that the CMC was recorded at concentration of $2.55515 \mathrm{~g} / \mathrm{L}$. After reaching the $\mathrm{CMC}$, the turbidity remains relatively constant or changes with a lower slope.

2.5. Synthesis of Iron Nanoparticles NZVI. Iron nanoparticles were synthesized by mixing the precursor solution with a reducing agent solution. The precursor solution was made of $4.0 \mathrm{~g}$ of ferric chloride $\left(\mathrm{FeCl}_{3}\right)$ in $50 \mathrm{~mL}$ of deionized water. $6.0 \mathrm{~g}$ of sodium borohydride $\left(\mathrm{NaBH}_{4}\right)$ was dissolved in $100 \mathrm{~mL}$ of deionized water to make the reducing agent solution. The reducing agent solution was immersed in the ice-bath before the precursor solution was added dropwise at a rate of $0.13 \mathrm{~mL} / \mathrm{s}$ using the microtube pump. The reaction was considered complete when bubbles were no longer generated. The product, black powder, was recovered using a strong magnet. The powder was washed twice using hot water and once using cold water to remove the residual by-product [19].
2.6. Synthesis of Surfactant Modified NZVI (SNZVI). $1 \mathrm{~g}$ of the synthesized NZVI was put into N2 purged of $2.5 \mathrm{~g} / \mathrm{L}$ nonionic surfactant (Tween 85 ) solutions in $60 \mathrm{~mL}$ bottle and was mixed continuously in end-over-end shaker during the night. Black precipitates were separated by centrifugation, washed twice with deionized water, and then dried in a vacuum oven for 1 day.

2.7. Characterization of Nanoscale Iron. Samples for transmission electron microscopy (TEM) were prepared by allowing a drop of the iron nanoparticles in ethanol solution to dry on a lacey-carbon film supported on a 300-mesh copper grid. Conventional bright-field imaging was carried out using a JEOL-JEM2100, Japan, operating at $200 \mathrm{kV}$. High-resolution lattice imaging was performed using a JEOL 2200FS TEM with a field-emission gun operating at $200 \mathrm{kV}$. The specific surface area (SSA) of NZVI and SNZVI was calculated after more than 4 particles TEM images were manually examined. The specific surface area (SSA) can be calculated by the following equation:

$$
\mathrm{SSA}=\frac{\text { Surface Area }}{\text { Mass }}=\frac{\pi d^{2}}{\rho(\pi / 6) d^{3}}=\frac{6}{\rho d},
$$

where $\rho$ is the density $\left(7.8 \mathrm{~g} / \mathrm{m}^{3}\right.$ for iron) of the solid particle, $d$ is the average particle size diameter by $\mu \mathrm{m}$, and the SSA values are given by $\mathrm{m}^{2} / \mathrm{g}$ or $\mathrm{m}^{2} \mathrm{~g}^{-1}$.

\subsubsection{Calculation of Specific Surface Area of Prepared SNZVI.} The properties of $\mathrm{Fe}^{0}$ and $\mathrm{Fe}^{0}$ emulsifier are provided in Table 1 . The calculated specific surface area was determined form at least five different TEM images. The calculated specific surface area of NZVI and SNZVI is $27.41 \mathrm{~m}^{2} / \mathrm{g}$ and $6.57 \mathrm{~m}^{2} / \mathrm{g}$, respectively, and is similar to those reported in the literature despite minor differences in the iron synthesis method. This means that Lee et al. [19] in his study found that the surface area of SNZVI was $37.07 \mathrm{~m}^{2} / \mathrm{g}$, BET surface area of NZVI was $25.01 \mathrm{~m}^{2} / \mathrm{g}$, and last value is less than the previous result reported by $\mathrm{Li}$ et al. [20] and Zhang [10], who found that the surface area of NZVI was $33.5 \mathrm{~m}^{2} / \mathrm{g}$. However, Ai et al. [21] reported that the surface area of NZVI was ranged $10-40 \mathrm{~m}^{2} / \mathrm{g}$, depending on synthesis condition of NZVI. The volume size distribution indicated a significant size reduction in SNZVI; this means that the nonionic surfactant (Tween 85) monomers were coated on the surface of NZVI and improved both of mass transport and size distribution between NZVI and TCE molecules. Generally, the theoretical specific surface area for $60 \mathrm{~nm}$ iron particles is $12,820 \mathrm{~m}^{2} / \mathrm{kg}$ equivalent to $1.2821 E^{-05} \mathrm{~m}^{2} / \mathrm{kg}$.

2.8. TCE Removal with SNZVI. A fixed $500 \mathrm{~g}$ soil having a diameter range $0.5-1 \mathrm{~mm}$ was polluted with $10 \mathrm{~mL}$ TCE and input inside glass column of $2.5 \mathrm{~cm}$ diameter $\times 300 \mathrm{~cm}$ length. The NZVI solution was prepared from reduction of $\mathrm{FeCL}_{3}$ by $\mathrm{NaBH}_{4}$ and coating with $2.5 \mathrm{~g}$ nonionic surfactant (Tween 85) to produce iron nanoparticle concentration of $0.1 \mathrm{~g} / \mathrm{L}$. Then they were poured into contaminated soil and left to stirring at a constant rate for 24 days. To confirm TCE degradation, chloride 
TABLE 1: Properties of NZVI and SNZVI nanoparticles.

\begin{tabular}{lcccc}
\hline & $\begin{array}{c}\text { Average particle size } \\
(\mu \mathrm{m})\end{array}$ & Shape & $\begin{array}{c}\text { Specific surface area }\left(\mathrm{m}^{2} / \mathrm{g}\right) \text { or }\left(\mathrm{m}^{2} \mathrm{~g}^{-1}\right) \\
\mathrm{SA}=6 /(D * p)\end{array}$ & $\begin{array}{c}\text { Density of iron } \\
\mathrm{g} / \mathrm{m}^{3} \text { or }\left(\mathrm{m}^{3} \mathrm{~g}^{-1}\right)\end{array}$ \\
\hline NZVI & 0.02806 & Spherical & 27.41378365 & 7.8 \\
SNZVI & 0.116935 & Spherical & 6.578276557 & 7.8 \\
\hline
\end{tabular}

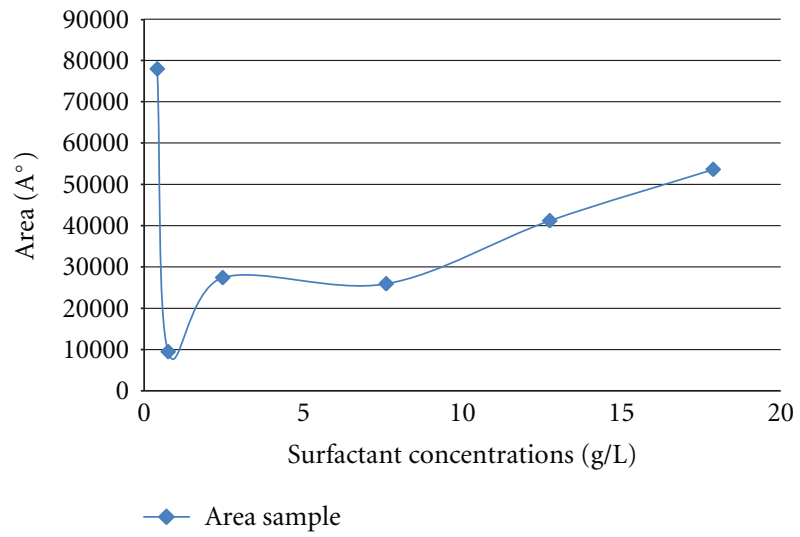

FIgURE 2: Critical micelle concentrations of nonionic surfactant versus TCE distribution in the aqueous phase as a function of area $\mathrm{A}^{\circ}$.

ion was measured with oyster conductivity-temperaturemeter model EXTECH 341350A-P equipped with mini $\mathrm{pH}$ electrode and choice of glass/polymer conductivity cell. The reductive dechlorination of TCE was measured as a function of increasing chloride ion.

\section{Results and Discussion}

At some industrial sites, free-phase chlorinated solvents in soils and aquifers impose potential threats to groundwater. Remediation of dense nonaqueous phase liquids (DNAPLs) presents a great challenge to modern remediation science and technology. Trichloroethylene (TCE) is a representative dense nonaqueous phase liquid (DNAPL) in soil.

3.1. TCE Dissolved in Water Solution. High performance liquid chromatography (HPLC) was used to monitor TCE concentration in presence of different surfactant concentrations. Figure 2 shows that maximum TCE recorded concentration was reflected to the area equivalent to $27420^{\circ} \mathrm{A}$ and closed to CMC of Tween 85 at $2.55515 \mathrm{~g} / \mathrm{L}$.

3.2. TEM Analysis of NZVI and SNZVI. Morphological analysis of the samples was performed by means of TEM analysis (JEOL-JEM2100, Japan), which requires the dropping of dispersed particles onto a $\mathrm{Cu}$ grid. The morphologies of NZVI and SNZVI identification from TEM images are shown in Figures 3 and $4(\mathrm{a})-4(\mathrm{~d})$, in which the individual particles of NZVI and SNZVI appear spherical and have average diameter of about $28.06 \mathrm{~nm}$ and $116 \mathrm{~nm}$, respectively.
The characterization of the nanostructure of NZVI in Figure 3 shows a bright field TEM micrograph of a typical NZVI cluster. The nanoparticles appear agglomerated, forming chain-like formations due to magnetic and electrostatic interactions. It is clearly shown in the image that a single particle comprises of a dense core surrounded by a thin shell exhibiting markedly less contrast than the interior core. The iron nanoparticles are spherical, characteristic of particles precipitated in solution. The particle sizes ranged from three to hundred and eleven of nanometers. The TEM image also shows that most particles formed chain-like aggregates.

With respect to $\mathrm{Fe}^{0}$ emulsifier (SNZVI) in Figures 4(a)$4(\mathrm{~d})$, it is clear that the $\mathrm{Fe}^{0}$ emulsifier presents a finer particle size than bare NZVI. This is due to the presence of surfactant that adapted particle size of NZVI, and then such many finer nanoparticles with sizes of 8.03-39.11 nm and 190-230 nm were observed packing together into larger particles with size of $116 \mathrm{~nm}$.

The properties of NZVI and SNZVI nanoparticles are given in Table 1 . It can be generally concluded that all of these iron nanoparticles (NZVI and SNZVI) are aggregated in chain structures due to both their magnetic properties and their tendency to remain in the most thermodynamically favorable state [22]. The SNZVI presents a finer particle size than bare NZVI $((3.46+13.38+6.26+7.2+110) / 5=$ $28.06 \mathrm{~nm})$. For the grained surface of the SNZVI, many finer nanoparticles with sizes of 8.03-39.11 nm and 190-230 nm were observed packing together into larger particles with size of $116 \mathrm{~nm}$ (see the TEM images).

It is known that the engineered nanomaterials have found increasing applications in environmental technologies, including water and wastewater treatment, air, water and soil remediation, and hazardous waste treatment, owing their superior reactivity towards a variety of recalcitrant contaminants and their enhanced capacities for contaminant abatement [23-25]. Amongst this promising class of remediation agents, nanoscale zero-valent iron (NZVI) has perhaps received the most attention and has been shown to effectively degrade a wide spectrum of water contaminants, such as halogenated hydrocarbons, nitroaromatic compounds, azo dyes, perchlorate, nitrate, hexavalent chromium, and various heavy metal ions [24, 26-31].

3.3. Degradation of TCE Concentration with Reaction Time. The change of TCE concentration with reaction time is shown in Figure 5. The TCE was removed from initial $10 \mathrm{~g} / \mathrm{L}$ to almost $7.017 \mathrm{~g} / \mathrm{L}$ during $48 \mathrm{~h}$. The degradation of TCE occurred within first 6 days and there was only little change in TCE concentration after the 8th day. At the beginning of interaction between $10 \mathrm{~g} / \mathrm{L}$ TEC and SNVI, the degradation of TCE going at high speed and irregularity shape up to144 


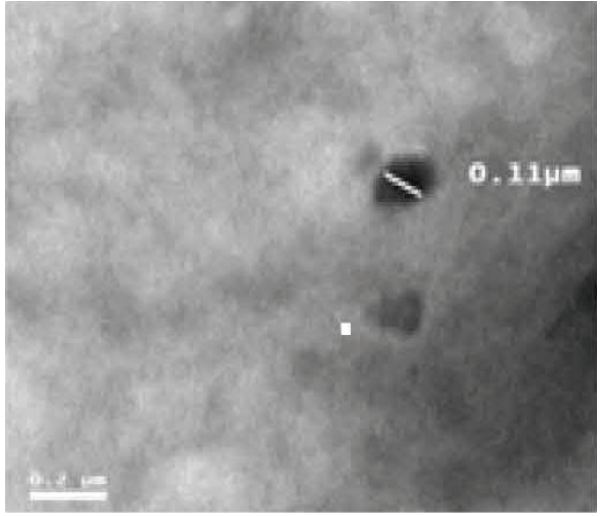

(a)

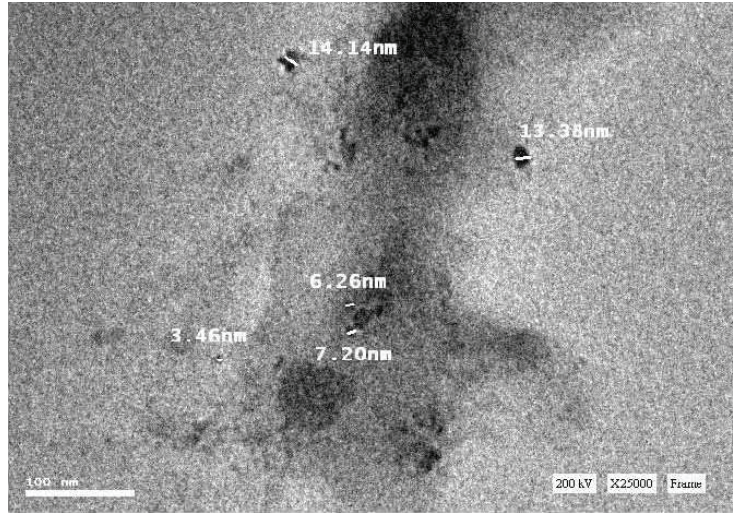

(b)

FIgURE 3: The TEM images of the laboratory-synthesized iron nanoparticles (NZVI). A single particle of $110 \mathrm{~nm}$ in (a) and the aggregates of iron particles on the outside figure. The diameter of aggregates in chains of NZVI $(3.46+13.38+6.26+7.2+110) / 5=28.06$.

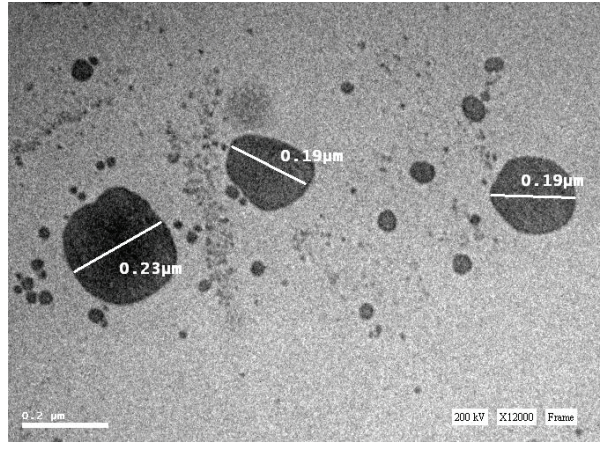

(a)

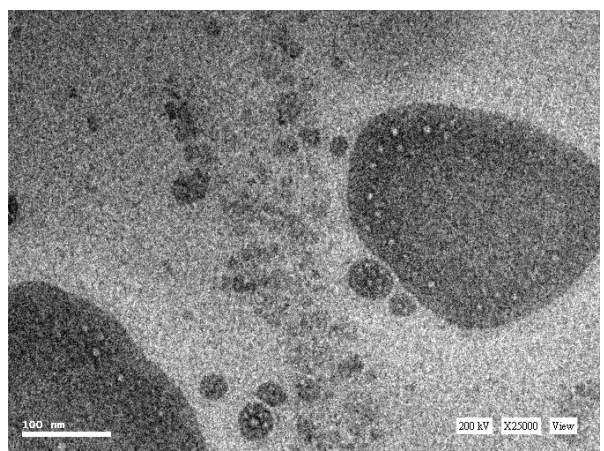

(c)

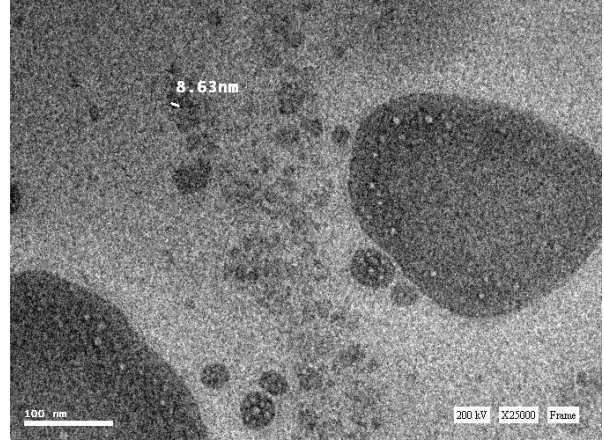

(b)

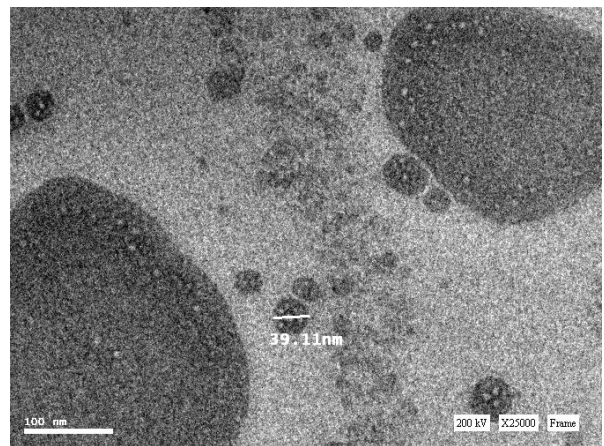

(d)

FIgure 4: ((a) and (b)) The TEM images of the laboratory-synthesized iron nanoparticles (SNZVI). The TEM diameter of aggregates in chains of SNZVI 190, 230, and 8.63, the micrograph of nanoparticle agglomerate showing the core-shell morphology and the variation in shell thickness observed at different locations of the agglomerate. Also, the figures show phase contrast TEM image showing a continuous surface amorphous layer that encapsulates the agglomerate. ((c) and (d)) The scale bar is $100 \mathrm{~nm}$ for image. The finer nanoparticles were packing together into larger particles with diameter of $39.11 \mathrm{~nm}$.

hours, then a significant regular decrease in the degradation curve starts at time of 168 hours and $6.69919 \mathrm{~g} / \mathrm{L}$ of TCE, followed by approximately fixed line until the end of reaction at 456 hours and $1.78 \mathrm{~g} / \mathrm{L}$ TCE. It is likely that the emergence of the curve at the beginning of the interaction between the ups and downs is due to degradation of TCE and production of precursor from ethane and ethylene, our suggestion agrees with the authors of [4-6] who stated that the proposed reaction pathways for TCE degradation are $\beta$-elimination (primary), hydrogenation (minor), and hydrogenolysis (minor). The first two mechanisms explain the formation of ethene and ethane, while a minor portion of TCE decomposed by the third can result in the formation of cis-dichloroethene (DCE) and vinyl chloride (VC). 


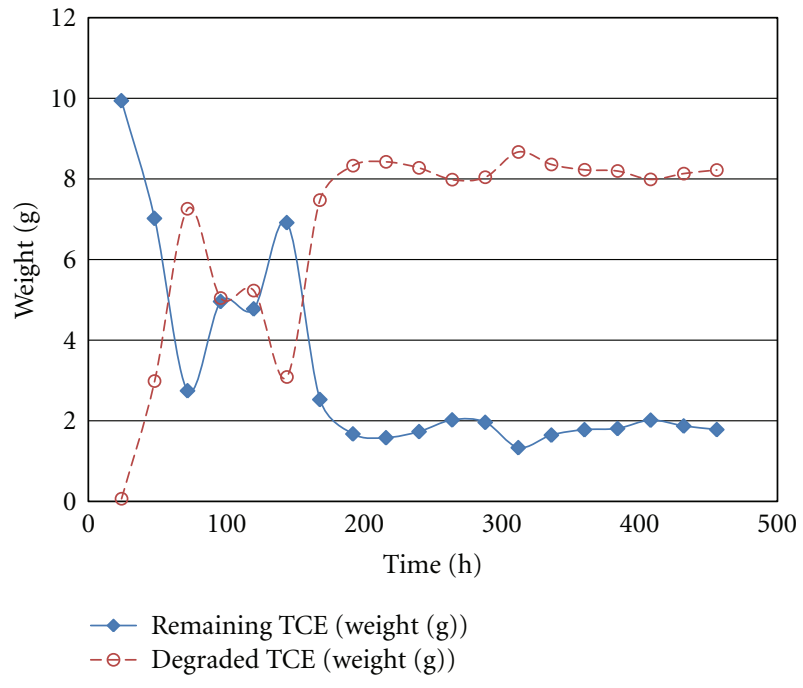

FIGURE 5: Efficiency of TCE degradation as a function of weight (g) against time.

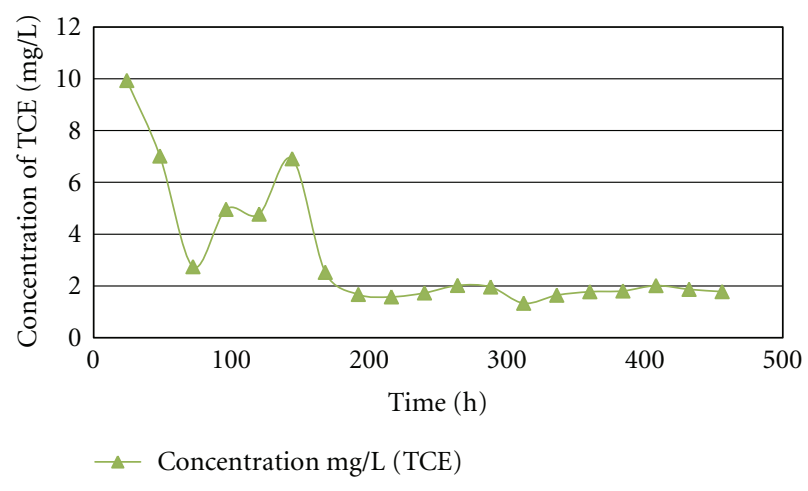

FIgURe 6: Degradation of TCE in soil versus time.

On the other hand, the highly reactive, nanoscale particles containing ZVI are quickly surrounded by a passivating layer, such as a shell of oxide which limits the ZVI corrosion rate [32].

Zhang [10] demonstrated that NZVI particles could remain reactive for 6 to 8 weeks in a water suspension in the laboratory. However, these highly reactive nanoscale particles change over time, with handling, during storage (in a slurry of water) and with exposure to natural environments where constituents in groundwater will decrease the reactivity of the particle surface.

Liu et al. [6] discussed in his work the TCE reaction rates, pathways, and efficiency of two nanoscale $\mathrm{Fe}^{0}$ particles measured in batch reactors: particles synthesized from sodium borohydride reduction of ferrous iron $(\mathrm{Fe} / \mathrm{B})$ and commercially available particles (RNIP).

\subsection{Efficiency of TCE Degradation as a Function of Weight.} Figure 6 exhibits the efficiency of TCE degradation as a function of weight and time, it is clear that at the first 72 hours a sharp increasing in degradation efficiency followed

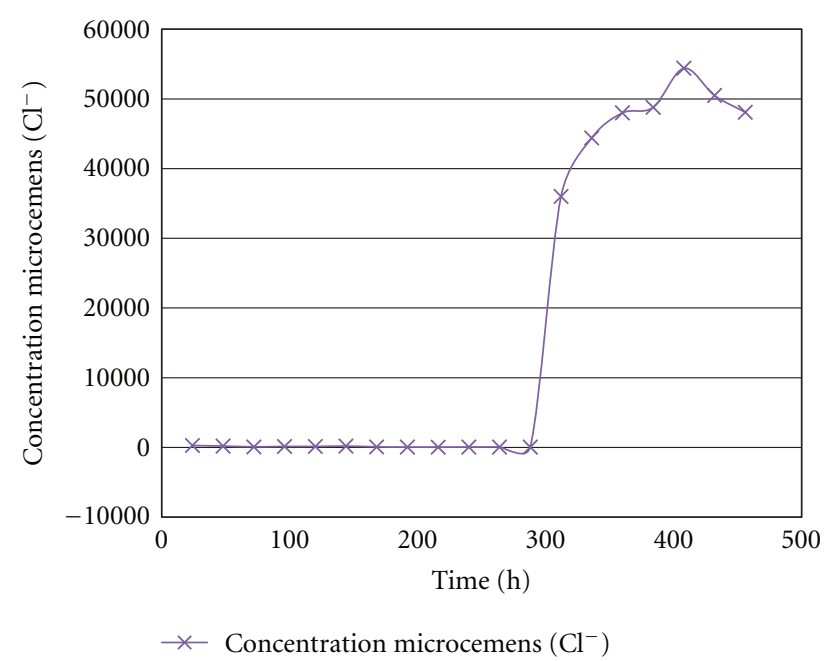

Figure 7: Effect of SNZVI on the Conc. of Chloride ion.

by unexpected behavior in degradation efficiency located 96 hours up to 144 hours occurred, otherwise from the degradation curve returned back to the expected behavior beginning at 168 hours till the end of degradation time, the overall degradation weight percentage from the beginning of interaction till the end is equivalent to $82.2 \%$.

3.5. Effect of SNZVI on the Concenteration of Chloride Ion. Theoretically, chloride ions are a good function for TCE reductive degradation [33]. Figure 7 exhibits the relation between chloride ions produced from TCE degradation in the presence of SNZVI. As observed from graph, the concentration of chloride ions remains unchanged till 288 hours and 52.95 microcemens (Cl-), after that a significant highly jumping in chloride ions concentration reached to 48100 microcemens at 456 hours. The undetected chloride ions in the first days may be due to consumption of some ions for producing some reactive intermediates such as vinyl chloride and di-chloroethylene (DCE); thereby, these intermediates are very low levels and disappeared quickly. Our suggestion is in agreement with Liu et al. [34] who stated that under iron-limited conditions, Fe/B transformed TCE to nonchlorinated hydrocarbons, mostly even-numbered saturated alkanes $(87.4 \%)$, but other saturated and unsaturated hydrocarbons were also detected. Ethene was a reactive intermediate and transformed to ethane. No acetylene was detected. Vinyl chloride and cis-di-chloroethylene (DCE) were detected as reactive intermediates in the reactor at very low levels and disappeared quickly. The final products were ethane $(70 \%)$ and C3-C6 coupling products ( 30\%). A similar distribution was found for $\mathrm{Fe} / \mathrm{B}$ using excess iron: $80 \%$ ethane and $\sim 20 \%$ C3-C6 coupling products.

3.6. Effect of SNZVI on the TCE Degradation Rate. As shown in Figure 8, the reaction time was $500 \mathrm{~h}$, and the logarithm of initial to final concentrations showed linear relationship and the observed rate constant was approximately $4 \times$ $10^{-4} \mathrm{~h}^{-1}$. The dechlorination of TCE by SZVI can be 


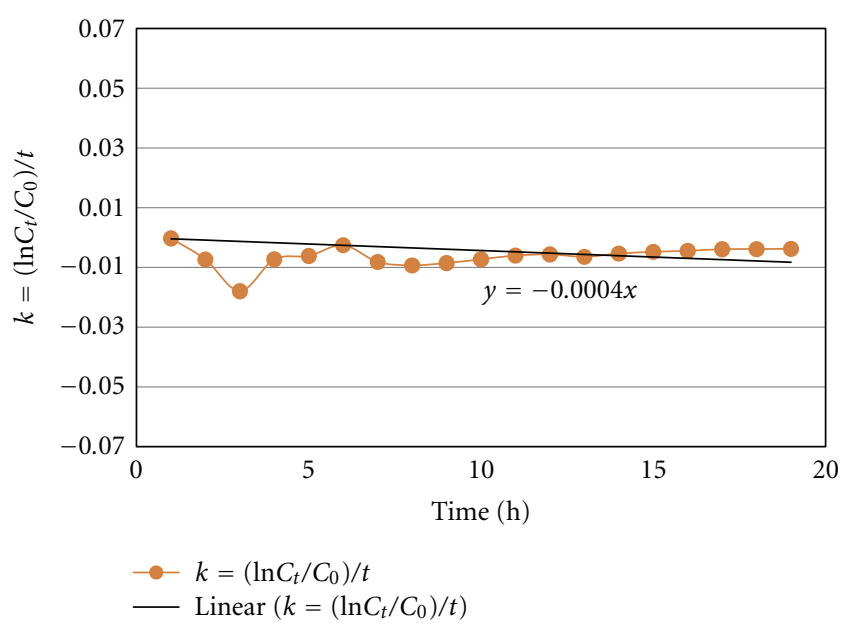

Figure 8: Constant of degradation rate of TCE using SNZVI.

assumed aa pseudo-first-order reaction. The reaction rate can be calculated by Johnson et al.'s equation [35].

To determine reaction constant, logarithm of TCE concentrations was plotted versus time as follows:

$$
\frac{d C}{d t}=-K_{\mathrm{obs}} X C
$$

where $C$ is aqueous contaminant concentration and $K_{\text {obs }}$ is observed pseudo-first-order rate constant $\left(\mathrm{h}^{-1}\right)$. The observed rate constant differs from experimental condition such as concentration of reactive material (ZVI) or reactive surface area. The specific rate constant $\left(K_{\mathrm{SA}}, \mathrm{h}^{-1} \mathrm{~m}^{-1} \mathrm{~L}\right)$ was developed as follows:

$$
\begin{gathered}
\frac{d c}{d t}=-K_{\mathrm{SA}} \alpha_{\mathrm{s}} \rho_{m} \mathrm{XC}, \\
K_{\mathrm{SA}}=\frac{K_{\mathrm{obs}}}{\alpha_{s} \rho_{m}},
\end{gathered}
$$

where $\alpha_{s}$ is the surface area of ZVI $\left(\mathrm{m}^{2} / \mathrm{g}\right)$ and $\rho_{m}$ is the ZVI concentration in aqueous phase $(\mathrm{g} / \mathrm{L})$. The rate constant and specific rate constant of the TCE degradation using SZVI are shown in Table 2. It was found that the specific rate constant $\left(K_{\text {obs }}\right)$ of TCE dechlorination by SZVI was $\left(6.081 \times 10^{-4} \mathrm{~L} \cdot \mathrm{h}^{-1} \cdot \mathrm{m}^{-2}\right)$ and is approximately 23 -fold lower than that recorded by Liu et al. [6], hence it is found that the measured specific rate constant $\left(K_{\mathrm{obs}}\right)$ of TCE dechlorination by Fe/B is $\left(1.4 \times 10^{-2} \mathrm{~L} \mathrm{~h}^{-1} \mathrm{~m}^{-2}\right)$. In contradiction to Liu et al. [6], our results are similar to the results recorded by $[7,36]$, who reported that the specific rate constant $\left(K_{\mathrm{obs}}\right)$ of TCE reaction rates by nanoscale iron is $\left(2-3 \times 10^{-3} \mathrm{Lh}^{-1} \mathrm{~m}^{-2}\right)$ and is similar to or slightly higher than those for iron filings $\left(\sim 10^{-4} \times 10^{-3} \mathrm{~L} \mathrm{~h}^{-1} \mathrm{~m}^{-2}\right)$ [35], but their significantly larger specific surface area makes them attractive for field application.

Generally, the dechlorination rate of halogenated compounds increases with the number of halogenated radicals, and the degradation rates varied from $10^{-1}$ to $10^{-6} \mathrm{~L} / \mathrm{h} / \mathrm{m}$ [37].

In addition, Wang and Zhang [7] and Schrick et al. [36] reported that the surface area normalized TCE reaction rates by nanoscale iron is $\left(2-3 \times 10^{-3} \mathrm{~L} \mathrm{~h}^{-1} \mathrm{~m}^{-2}\right)$ and is similar to or slightly higher than those for iron filings $\left(10^{-4}-\right.$ $10^{-3} \mathrm{~L} \mathrm{~h}^{-1} \mathrm{~m}^{-2}$ ) [35], but their significantly larger specific surface area makes them attractive for field application. As with iron filings, nonchlorinated hydrocarbons (C2-C5) were observed as the final products from TCE degradation by nanoscale iron, but details of the product distribution and reaction kinetics have not been described, and it is not clear if nanoscale iron dechlorinates TCE through the same pathways as iron filings $[7,36]$.

The Proposed TCE Dechlorination Reactions Mechanism. The authors of $[7,13,28,38]$ have demonstrated that treatment of chlorinated ethenes such as TCE with NZVI particles is more rapid than with conventional forms of granular iron. Nanoscale ZVI is significantly more reactive than microscale ZVI or iron powders because the smaller particle size gives the NZVI a larger surface area per unit mass. The degradation of chlorinated solvents by ZVI regardless of particle size is believed to occur via both reductive dechlorination and $\beta$-elimination [39]. The dechlorination reactions occur at the iron surface and require excess electrons produced from the corrosion of the ZVI in water. Through this process, the target chemicals undergo sequential dechlorination steps, resulting in the formation of nonchlorinated hydrocarbon products (e.g., ethene and ethane). The degradation of TCE may also occur via $\beta$-elimination where TCE is converted to chloroacetylene, which is further dechlorinated to acetylene. Acetylene is subsequently degraded to ethene and ethane. In general, less is known about the reaction kinetics and products formed during TCE dechlorination by iron nanoparticles without a catalyst metal. The authors of [39] reported that the TCE dechlorination pathways by iron filings give acetylene products from $\beta$-elimination and ethene from hydrogenolysis, whereas the intermediate compounds (e.g., chloroacetylene, dichloroethenes, and vinyl chloride) are not included. The authors of [40] reported that the direct TCE dechlorination using Pd-catalyzed gives ethane. A direct pathway does not necessitate new pathways than those reported for iron; if, for example, the intermediate compounds do not desorb from the particle surface before complete reduction to ethane and are not observed.

\section{Conclusion}

In summary, ZVI was coated with nonionic surfactant (Tween 85). Nonionic surfactants used in this work enhanced TCE desorption at concentrations below or above the critical micelle concentration (CMC).

The observed rate constant $\left(K_{\text {obs }}\right)$ and specific rate constant $\left(K_{\mathrm{SA}}\right)$ of SZVI nanoparticles were $1.40 \times 10^{-2} \mathrm{~h}^{-1}$ and $6.081 \times 10^{-4} \mathrm{~L} \cdot \mathrm{h}^{-1} \cdot \mathrm{m}^{-2}$, respectively.

Because small quantity of SZVI was used in the degradation of TCE, the rate constant was lower than published 
TABLE 2: Rate constant and specific rate constant of prepared SNZVI with TCE.

\begin{tabular}{lcccc}
\hline Pollutant & $\begin{array}{c}K_{\text {obs }} \text { rate } \\
\text { constant }(\text { day })\end{array}$ & $\begin{array}{c}K_{\mathrm{SA}} \text { specific rate constant } \\
\left(\mathrm{h}^{-1} \mathrm{~m}^{-1} \mathrm{~L}\right)\end{array}$ & $\begin{array}{c}\text { Specific surface area of SNZVI }\left(\mathrm{m}^{2} \mathrm{~g}^{-1}\right) \\
A_{s}\end{array}$ & $\begin{array}{c}\text { Mass concentration of SNZVI } \\
\left(\mathrm{g}^{-1} \mathrm{~L}\right) \rho \mathrm{m}\end{array}$ \\
\hline TCE & $4.000 E^{-04}$ & $6.081 E^{-04}$ & 6.578276557 & 0.1 \\
\hline
\end{tabular}

values by 23 orders of magnitude. Therefore, SZVI can be used efficiently in the degradation of chlorinated solvent in aqueous solution and porous media.

Based on the pseudo-first-order reaction rate law, the presence of Tween 85 increased the TCE removal rate of degrading TCE from soil. It may be possible to protect the $\mathrm{Fe}^{0}$ core by using surface coatings other than noble metals, such as surfactants.

\section{References}

[1] M. Zhang, F. He, D. Zhao, and X. Hao, "Degradation of soil-sorbed trichloroethylene by stabilized zero valent iron nanoparticles: effects of sorption, surfactants, and natural organic matter," Water Research, vol. 45, no. 7, pp. 2401-2414, 2011.

[2] D. R. Burris, T. J. Campbell, and V. S. Manoranjan, "Sorption of trichloroethylene and tetrachloroethylene in a batch reactive metallic iron-water system," Environmental Science and Technology, vol. 29, no. 11, pp. 2850-2855, 1995.

[3] O. I. Mohammad and T. C. G. Kibbey, "Dissolution-induced contact angle modification in dense nonaqueous phase liquid/water systems," Environmental Science and Technology, vol. 39, no. 6, pp. 1698-1706, 2005.

[4] A. L. Roberts, L. A. Totten, W. A. Arnold, D. R. Burris, and T. J. Campbell, "Reductive elimination of chlorinated ethylenes by zero-valent metals," Environmental Science and Technology, vol. 30, no. 8, pp. 2654-2659, 1996.

[5] C. Su and R. W. Puls, "Kinetics of trichloroethene reduction by zerovalent iron and tin: pretreatment effect, apparent activation energy, and intermediate products," Environmental Science and Technology, vol. 33, no. 1, pp. 163-168, 1999.

[6] Y. Liu, S. A. Majetich, R. D. Tilton, D. S. Sholl, and G. V. Lowry, "TCE dechlorination rates, pathways, and efficiency of nanoscale iron particles with different properties," Environmental Science and Technology, vol. 39, no. 5, pp. 1338-1345, 2005.

[7] C.-B. Wang and W.-X. Zhang, "Synthesizing nanoscale iron particles for rapid and complete dechlorination of TCE and PCBs," Environmental Science and Technology, vol. 31, no. 7, pp. 2154-2156, 1997.

[8] S. Choe, S. H. Lee, Y. Y. Chang, K. Y. Hwang, and J. Khim, "Rapid reductive destruction of hazardous organic compounds by nanoscale Fe0," Chemosphere, vol. 42, no. 4, pp. 367-372, 2001.

[9] US EPA, Workshop on Nanotechnology for Site Remediation, U.S. Department of Commerce, Washington, DC, USA, 2005.

[10] W. Zhang, "Nanoscale iron particles for environmental remediation: an overview," Journal of Nanoparticle Research, vol. 5, pp. 323-332, 2003.

[11] F. He and D. Zhao, "Preparation and characterization of a new class of starch-stabilized bimetallic nanoparticles for degradation of chlorinated hydrocarbons in water," Environmental Science and Technology, vol. 39, no. 9, pp. 3314-3320, 2005.
[12] F. He, D. Zhao, J. Liu, and C. B. Roberts, "Stabilization of Fe-Pd nanoparticles with sodium carboxymethyl cellulose for enhanced transport and dechlorination of trichloroethylene in soil and groundwater," Industrial and Engineering Chemistry Research, vol. 46, no. 1, pp. 29-34, 2007.

[13] D. W. Elliott and W. X. Zhang, "Field assessment of nanoscale bimetallic particles for groundwater treatment," Environmental Science and Technology, vol. 35, no. 24, pp. 4922-4926, 2001.

[14] J. Quinn, C. Geiger, C. Clausen et al., "Field demonstration of DNAPL dehalogenation using emulsified zero-valent iron," Environmental Science and Technology, vol. 39, no. 5, pp. 13091318, 2005.

[15] P. Mayer, M. M. Fernqvist, P. S. Christensen, U. Karlson, and S. Trapp, "Enhanced diffusion of polycyclic aromatic hydrocarbons in artificial and natural aqueous solutions," Environmental Science and Technology, vol. 41, no. 17, pp. 6148-6155, 2007.

[16] S. K. Park and A. R. Bielefeldt, "Non-ionic surfactant flushing of pentachlorophenol from NAPL-contaminated soil," Water Research, vol. 39, no. 7, pp. 1388-1396, 2005.

[17] C. C. West and J. H. Harwell, "Surfactants and subsurface remediation," Environmental Science and Technology, vol. 26, no. 12, pp. 2324-2330, 1992.

[18] M. C. Shin, H. D. Choi, D. H. Kim, and K. Baek, "Effect of surfactant on reductive dechlorination of trichloroethylene by zero-valent iron," Desalination, vol. 223, no. 1-3, pp. 299-307, 2008.

[19] Y. C. Lee, C. W. Kim, J. Y. Lee, H. J. Shin, and J. W. Yang, "Characterization of nanoscale zero valent iron modified by nonionic surfactant for trichloroethylene removal in the presence of humic acid: a research note," Desalination and Water Treatment, vol. 10, no. 1-3, pp. 33-38, 2009.

[20] L. Li, M. Fan, R. C. Brown et al., "Synthesis, properties, and environmental applications of nanoscale iron-based materials: a review," Critical Reviews in Environmental Science and Technology, vol. 36, no. 5, pp. 405-431, 2006.

[21] Z. Ai, L. Lu, J. Li, L. Zhang, J. Qiu, and M. Wu, "Fe@ $\mathrm{Fe}_{2} \mathrm{O}_{3}$ core-shell nanowires as iron reagent. 1. Efficient degradation of rhodamine by a novel sono-fenton process," Journal of Physical Chemistry C, vol. 111, no. 11, pp. 4087-4093, 2007.

[22] S. R. Kanel, D. Nepal, B. Manning, and H. Choi, "Transport of surface-modified iron nanoparticle in porous media and application to arsenic(III) remediation," Journal of Nanoparticle Research, vol. 9, no. 5, pp. 725-735, 2007.

[23] B. Karn, T. Kuiken, and M. Otto, "Nanotechnology and in situ remediation: a review of the benefits and potential risks," Environmental Health Perspectives, vol. 117, no. 12, pp. 18231831, 2009.

[24] X. Q. Li, D. W. Elliott, and W. X. Zhang, "Zero-valent iron nanoparticles for abatement of environmental pollutants: materials and engineering aspects," Critical Reviews in Solid State and Materials Sciences, vol. 31, no. 4, pp. 111-122, 2006. 
[25] P. G. Tratnyek and R. L. Johnson, "Nanotechnologies for environmental cleanup," Nano Today, vol. 1, no. 2, pp. 44-48, 2006.

[26] S. R. Kanel, B. Manning, L. Charlet, and H. Choi, "Removal of arsenic(III) from groundwater by nanoscale zero-valent iron," Environmental Science and Technology, vol. 39, no. 5, pp. 12911298, 2005.

[27] H.-L. Lien and W.-X. Zhang, "Nanoscale Pd/Fe bimetallic particles: catalytic effects of palladium on hydrodechlorination," Applied Catalysis B, vol. 77, no. 1-2, pp. 110-116, 2007.

[28] G. V. Lowry and K. M. Johnson, "Congener-specific dechlorination of dissolved PCBs by microscale and nanoscale zerovalent iron in a water/methanol solution," Environmental Science and Technology, vol. 38, no. 19, pp. 5208-5216, 2004.

[29] S. M. Ponder, J. G. Darab, and T. E. Mallouk, "Remediation of $\mathrm{Cr}(\mathrm{VI})$ and $\mathrm{Pb}(\mathrm{II})$ aqueous solutions using supported, nanoscale zero-valent iron," Environmental Science and Technology, vol. 34, no. 12, pp. 2564-2569, 2000.

[30] S. M. Ponder, J. G. Darab, J. Bucher et al., "Surface chemistry and electrochemistry of supported zerovalent iron nanoparticles in the remediation of aqueous metal contaminants," Chemistry of Materials, vol. 13, no. 2, pp. 479-486, 2001.

[31] D. Bhattacharyya, X. Jian, D. Meyer, Y. Tee, and L. Bachas, "Membrane-immobilized metal nanoparticles for environmental applications," in Proceedings of the The International Council of Museums (ICOM '05), Seoul, Korea, 2005.

[32] J. T. Nurmi, P. G. Tratnyek, V. Sarathy et al., "Characterization and properties of metallic iron nanoparticles: spectroscopy, electrochemistry, and kinetics," Environmental Science and Technology, vol. 39, no. 5, pp. 1221-1230, 2005.

[33] H. Kim, H. J. Hong, Y. J. Lee, H. J. Shin, and J. W. Yang, "Degradation of trichloroethylene by zero-valent iron immobilized in cationic exchange membrane," Desalination, vol. 223, no. 1-3, pp. 212-220, 2008.

[34] Y. Liu, S. A. Majetich, R. D. Tilton, D. S. Sholl, and G. V. Lowry, "TCE dechlorination rates, pathways, and efficiency of nanoscale iron particles with different properties," Environmental Science and Technology, vol. 39, no. 5, pp. 1338-1345, 2005.

[35] T. L. Johnson, M. M. Scherer, and P. G. Tratnyek, "Kinetics of halogenated organic compound degradation by iron metal," Environmental Science and Technology, vol. 30, no. 8, pp. 26342640, 1996.

[36] B. Schrick, J. L. Blough, A. D. Jones, and T. E. Mallouk, "Hydrodechlorination of trichloroethylene to hydrocarbons using bimetallic nickel-iron nanoparticles," Chemistry of Materials, vol. 14, no. 12, pp. 5140-5147, 2002.

[37] C. Merly and D. N. Lerner, "Remediation of chlorinated organic contaminants in fractured aquifers using zero-valent metal: report on laboratory trials," R\&D Technical Report P2-182/TR, Environment Agency, 2002, http://www.environment-agency.gov.uk/.

[38] H. L. Lien and W. X. Zhang, "Nanoscale iron particles for complete reduction of chlorinated ethenes," Colloids and Surfaces A, vol. 191, no. 1-2, pp. 97-105, 2001.

[39] W. A. Arnold and A. L. Roberts, "Pathway and kinetics of chlorinatedethylene and chlorinated acetylene reactionwith Fe(0) particles," Environmental Science \& Technology, vol. 34, no. 9, pp. PP1794-PP1805, 2000.

[40] G. V. Lowry and M. Reinhard, "Hydrodehalogenation of 1to 3-carbon halogenated organic compounds in water using a palladium catalyst and hydrogen gas," Environmental Science and Technology, vol. 33, no. 11, pp. 1905-1910, 1999. 

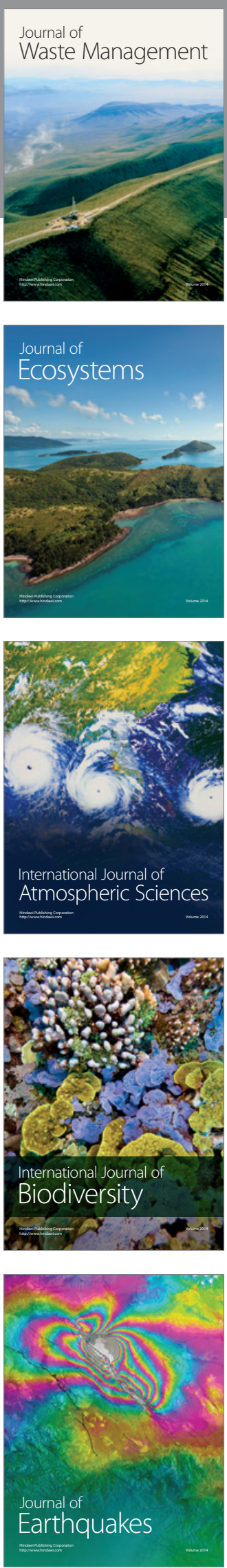
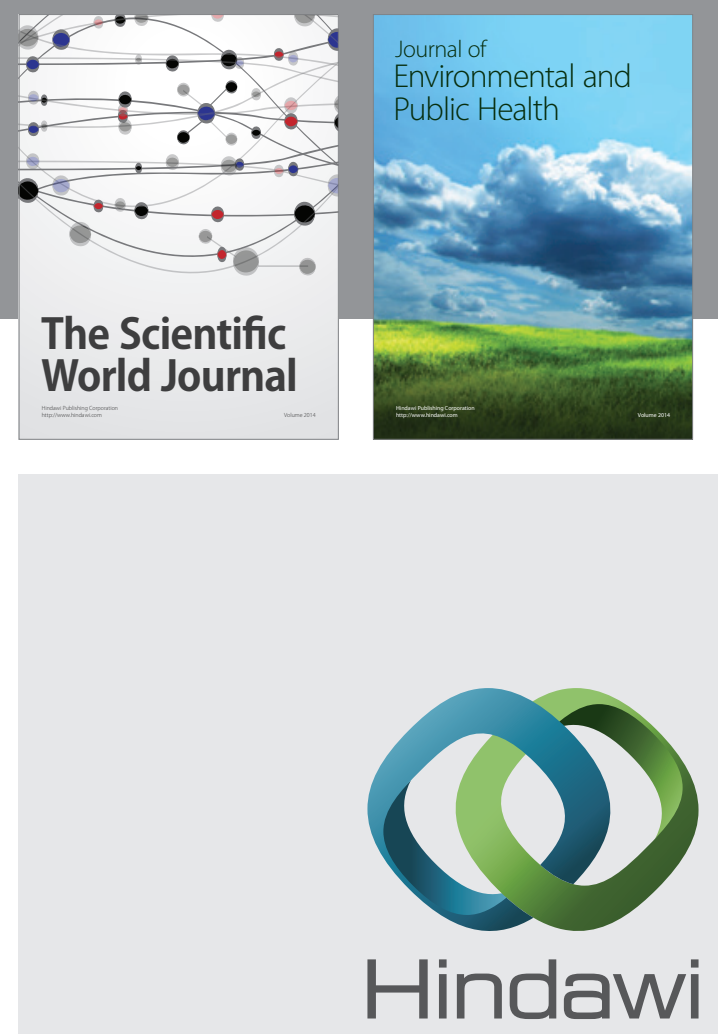

Submit your manuscripts at

http://www.hindawi.com
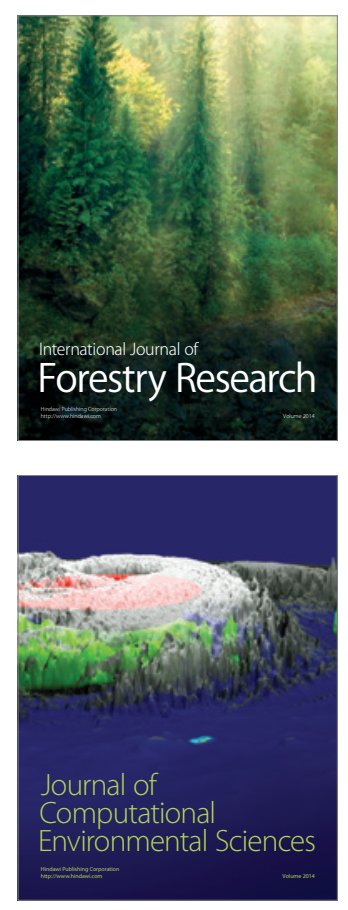
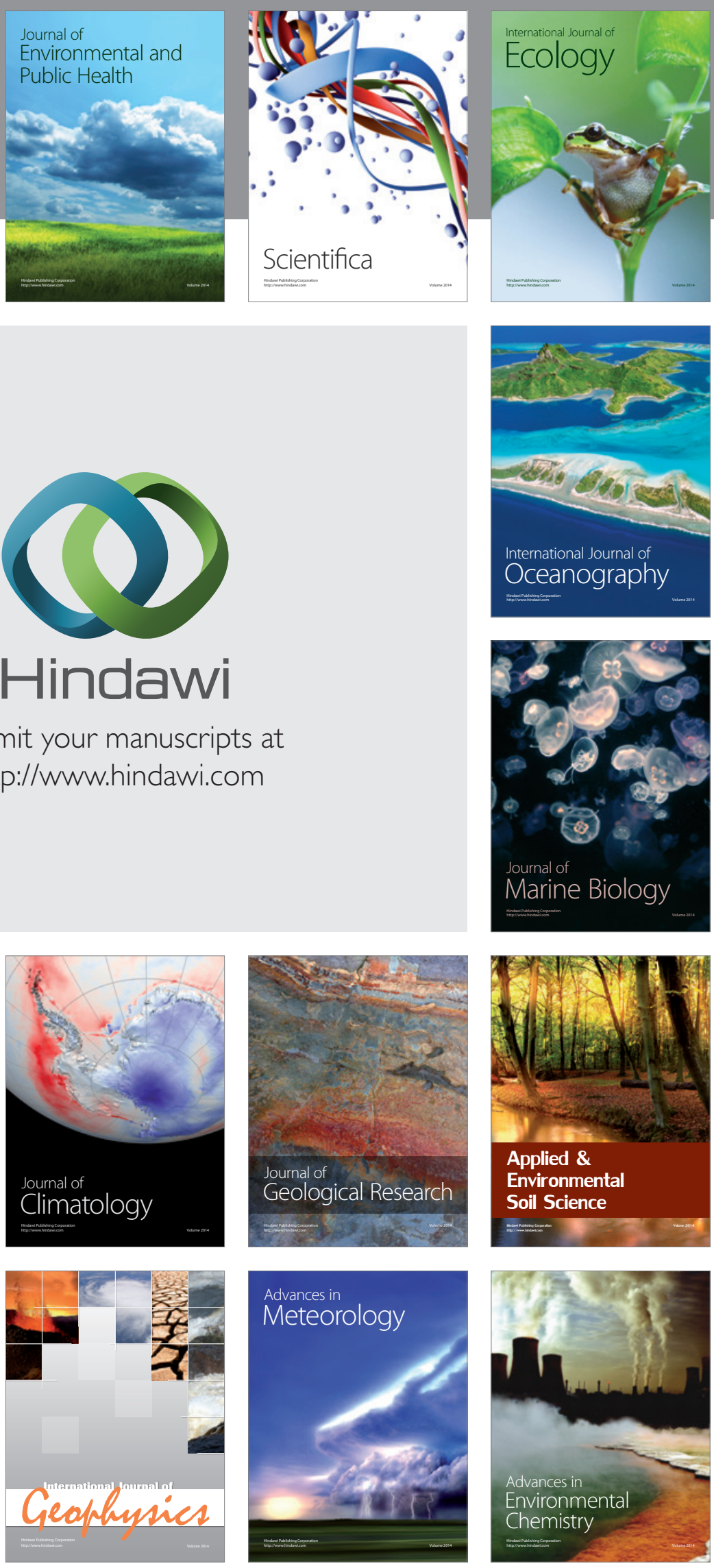